\title{
Active spacecraft potential control for Cluster - implementation and first results
}

\author{
K. Torkar ${ }^{1}$, W. Riedler ${ }^{1}$, C. P. Escoubet ${ }^{2}$, M. Fehringer ${ }^{2}$, R. Schmidt ${ }^{2}$, R. J. L. Grard ${ }^{2}$, H. Arends ${ }^{2}$, F. Rüdenauer ${ }^{3}$, \\ W. Steiger ${ }^{4}$, B. T. Narheim ${ }^{5}$, K. Svenes ${ }^{5}$, R. Torbert ${ }^{6}$, M. André ${ }^{7}$, A. Fazakerley ${ }^{8}$, R. Goldstein ${ }^{9}$, R. C. Olsen ${ }^{10}$, \\ A. Pedersen $^{11}$, E. Whipple ${ }^{12}$, and H. Zhao ${ }^{13}$ \\ ${ }^{1}$ Space Research Institute, Austrian Academy of Sciences, Schmiedlstrasse 6, 8042 Graz, Austria \\ ${ }^{2}$ Space Science Department of ESA/ESTEC, 2200 AG Noordwijk, The Netherlands \\ ${ }^{3}$ Now at: International Atomic Energy Agency, Safeguards Analytical Laboratory, 2444 Seibersdorf, Austria \\ ${ }^{4}$ Institute for Physics, Austrian Research Centers Seibersdorf, 2444 Seibersdorf, Austria \\ ${ }^{5}$ Forsvarets Forskningsinstitutt, Avdeling for Elektronikk, 2007 Kjeller, Norway \\ ${ }^{6}$ Space Science Center, Science and Engineering Research Center, University of New Hampshire, Durham, NH 03824, USA \\ ${ }^{7}$ Swedish Institute of Space Physics, Uppsala Division, 75121 Uppsala, Sweden \\ ${ }^{8}$ Dept. of Physics, Mullard Space Science Laboratory, University College London, Dorking, Surrey, UK \\ ${ }^{9}$ Southwest Research Institute, San Antonio, Texas 78238, USA \\ ${ }^{10}$ Physics Department, Naval Postgraduate School, Monterey, California 93943, USA \\ ${ }^{11}$ Dept. of Physics, University of Oslo, Blindern, Norway \\ ${ }^{12}$ University of Washington, Geophysics Department, Seattle, Washington 98195, USA \\ ${ }^{13}$ Center for Space Science and Applied Research, Chinese Academy of Sciences, Beijing 100080, P. R. China
}

Received: 17 April 2001 - Revised: 20 August 2001 - Accepted: 23 August 2001

\begin{abstract}
Electrostatic charging of a spacecraft modifies the distribution of electrons and ions before the particles enter the sensors mounted on the spacecraft body. The floating potential of magnetospheric satellites in sunlight very often reaches several tens of volts, making measurements of the cold (several eV) component of the ambient ions impossible. The plasma electron data become contaminated by large fluxes of photoelectrons attracted back into the sensors.

The Cluster spacecraft are equipped with emitters of the liquid metal ion source type, producing indium ions at 5 to $9 \mathrm{keV}$ energy at currents of some tens of microampere. This current shifts the equilibrium potential of the spacecraft to moderately positive values. The design and principles of the operation of the instrument for active spacecraft potential control (ASPOC) are presented in detail.
\end{abstract}

Experience with spacecraft potential control from the commissioning phase and the first two months of the operational phase are now available. The instrument is operated with constant ion current for most of the time, but tests have been carried out with varying currents and a "feedback" mode with the instrument EFW, which measures the spacecraft potential. That has been reduced to values according to expectations. In addition, the low energy electron measurements show substantially reduced fluxes of photoelectrons as expected. The flux decrease in photoelectrons returning to the spacecraft, however, occurs at the expense of an en-

Correspondence to: K. Torkar (klaus.torkar@oeaw.ac.at) larged sheath around the spacecraft which causes problems for boom-mounted probes.

Key words. Space plasma physics (spacecraft sheaths, wakes, charging); Instruments and techniques; Active perturbation experiments

\section{Introduction}

Solid bodies embedded in plasma and irradiated by the Sun acquire an electric potential that is determined by the equilibrium of the various charging currents. The relevant currents are due to photo-emission caused by sunlight, plasma currents due to ambient electrons and ions, and secondary electron currents caused by the impact of primary electrons and ions. In the plasmasphere, which is generally only briefly touched by the Cluster orbit, the plasma electron current to a spacecraft surface at the plasma potential is comparable or exceeds the total photoelectron current generated at the surface. Hence, the equilibrium potential is close to zero or negative. Outside the plasmasphere, i.e. almost throughout the orbit of Cluster, the plasma density drops to values well below some $100 \mathrm{~cm}^{-3}$, so that an increasingly small portion of the photoelectrons at high energy suffices to counterbalance the plasma electron current, which leads to significant positive potentials of the spacecraft. In extremely low density plasmas $\left(<0.1 \mathrm{~cm}^{-3}\right)$, such as in the lobes of the Earth's magnetotail, spacecraft potentials in sunlight conditions can 
reach values $>50 \mathrm{~V}$, as already shown by GEOS and ISEE observations (Pedersen et al., 1983).

Sensors for both ions and electrons suffer from high spacecraft potentials since the particles are accelerated or decelerated and their trajectories are modified in the sheath around the spacecraft. Some particles may not reach the sensor at all. Most of the photoelectrons at energies below the spacecraft potential are trapped in the sheath and eventually return to the surface of the sensor, causing an additional disturbance in the measurements and problems for the sensors.

The problems associated with spacecraft charging have been recognised very early (for reviews, see e.g. Grard, 1973; Whipple, 1981), and measures to improve the situation for the particle instruments have been sought. A first and necessary step consists of avoiding local (differential) charging of spacecraft surfaces, particularly near the particle sensors by making the entire surface of the spacecraft conductive, including the solar panel which has to be coated by indium-tin oxide. A second step is achieved by actively lowering the potential. The rationale for active spacecraft potential control has been established in the early 1980's (see, e.g. Pedersen et al., 1983) and has triggered the installation of instruments for the active control of the spacecraft potential on several spacecraft. A plasma source has been installed on the Polar spacecraft (Moore et al., 1995), whereas the principle applied on Cluster has been tested earlier on the Geotail (Schmidt et al., 1995), Interball-Auroral (Torkar et al., 1998), and Equator-S (Torkar et al., 1999) spacecraft.

The instrument itself has been described earlier (Riedler et al., 1997) in the version built for the first attempt to launch the Cluster spacecraft in 1996. For Cluster-II, several parts of the hardware and software have been modified, but the overall concept remains unchanged. The following sections provide a review of the instrument as it flies on board the Cluster spacecraft, but novel aspects are the prime focus. The last part of the paper presents first results from the mission.

The primary motivation for active spacecraft potential control on Cluster is to permit an almost complete measurement of the ambient plasma distribution functions both for electrons and ions by PEACE (Plasma Electron And Currents Experiment, Johnstone et al., 1997, this issue), and for ions by CIS (Cluster Ion Spectroscopy, Rème et al., 1997), respectively. Typical floating potentials of up to several tens of volts obscure or render impossible the measurement of the core of the ion-distribution function, which has a thermal energy comparable to the satellite potential. Densities calculated from particle measurements show large discrepancies from densities derived from wave experiments in these conditions. Measurements in eclipse made on ATS-6, SCATHA and DE-1 have shown the appearance of previously "hidden" ion populations, invisible in sunlight (Olsen, 1982).

When interpretating electron measurements, one encounters additional difficulties due to the contamination of the data by photoelectrons entering into the sensor. Moment calculations without any correction for spacecraft charging and photoelectrons would severely overestimate the density.

\section{Operating principle}

If one neglects ion currents and the secondary emission, and assumes the orbit-limited case, when the Debye length is much larger than the body (a typical situation in the outer magnetosphere) then a spacecraft in sunlight, yet outside the regions with extremely hot plasma, such as in an active plasmasheet, experiences a random electron current $I_{a 0}$ from the plasma to the satellite surface $A$ which is assumed here to be spherical. If the electron distribution can be approximated by a Maxwellian, one obtains

$I_{a 0}=\frac{A}{4} n_{e} e \sqrt{\frac{8 k T_{e}}{\pi m_{e}}}$

in the form given by Pedersen (1995) to the original equation developed by Mott-Smith and Langmuir (1926). For positive spacecraft potentials $V_{s}$, the plasma electron current is further approximated by

$$
\begin{gathered}
I_{a}=I_{a 0}\left(1+\frac{V_{s}}{V_{e}}\right) \\
V_{e}=\frac{k T_{e}}{e}
\end{gathered}
$$

where $e, n_{e}, m_{e}, T_{e}$ are the charge, density, mass, and temperature of the plasma electrons and $k$ is the Boltzmann constant. The area $A$ for a spherical spacecraft of radius $R$ is $4 \pi R^{2}$. With $A=20 \mathrm{~m}^{2}$ for a Cluster spacecraft and $V_{s}=0$, the plasma electron current of Eq. (1) becomes numerically:

$I_{a 0}=0.55 n_{e} \sqrt{k T_{e}} \quad[\mu \mathrm{A}]$

where $I_{a 0}$ is in $\mu \mathrm{A}, n_{e}$ is in electrons $\mathrm{cm}^{-3}$ and $k T_{e}$ is in $\mathrm{eV}$.

The photoelectron current $I_{p}$ is determined by the solar spectrum and the material properties of the surface. The photoelectron saturation current density $j_{p s}$ varies for different materials, and between laboratory and in-orbit measurements. Feuerbacher and Fitton 1972) quote laboratory data of $j_{p s}$ for several spacecraft materials in the range between 10 and $40 \mu \mathrm{Am}^{-2}$. Values up to 60 and $80 \mu \mathrm{A} \mathrm{m}^{-2}$ have been found in a study of ISEE-1, GEOS-1, GEOS-2 and Geotail potentials by Pedersen (1995). Part of this variability is explainble by different materials, surface finishes, and the ageing processes in the space environment.

Assuming a Maxwellian distribution of the photoelectron population with a mean energy $k T_{p}$, which is certainly only a very crude approximation, the current of photoelectrons which finally escapes from the sunlit surface $A_{s}$ into space and thereby contributes to the current balance is for positive spacecraft potential $A_{s}$ :

$I_{p}=A_{s} j_{p s} \exp \left(\frac{-e V_{s}}{k T_{p}}\right)$

Using experimental data from satellites, Pedersen (1995) found a best fit to the current-voltage characteristics for $V_{s}>$ $10 \mathrm{~V}$ by a sum of two exponentials with $j_{p s}=80 \mu \mathrm{A} \mathrm{m}{ }^{-2}$ and $3 \mu \mathrm{A} \mathrm{m}^{-2}$, and $k T_{p}=2 \mathrm{eV}$ and $7.5 \mathrm{eV}$, respectively, or

$$
j_{p}=80 \exp \left(\frac{-V_{s}}{2}\right)+3 \exp \left(\frac{-V_{s}}{7.5}\right) \quad\left[\mu \mathrm{A} \mathrm{m}^{-2}\right]
$$




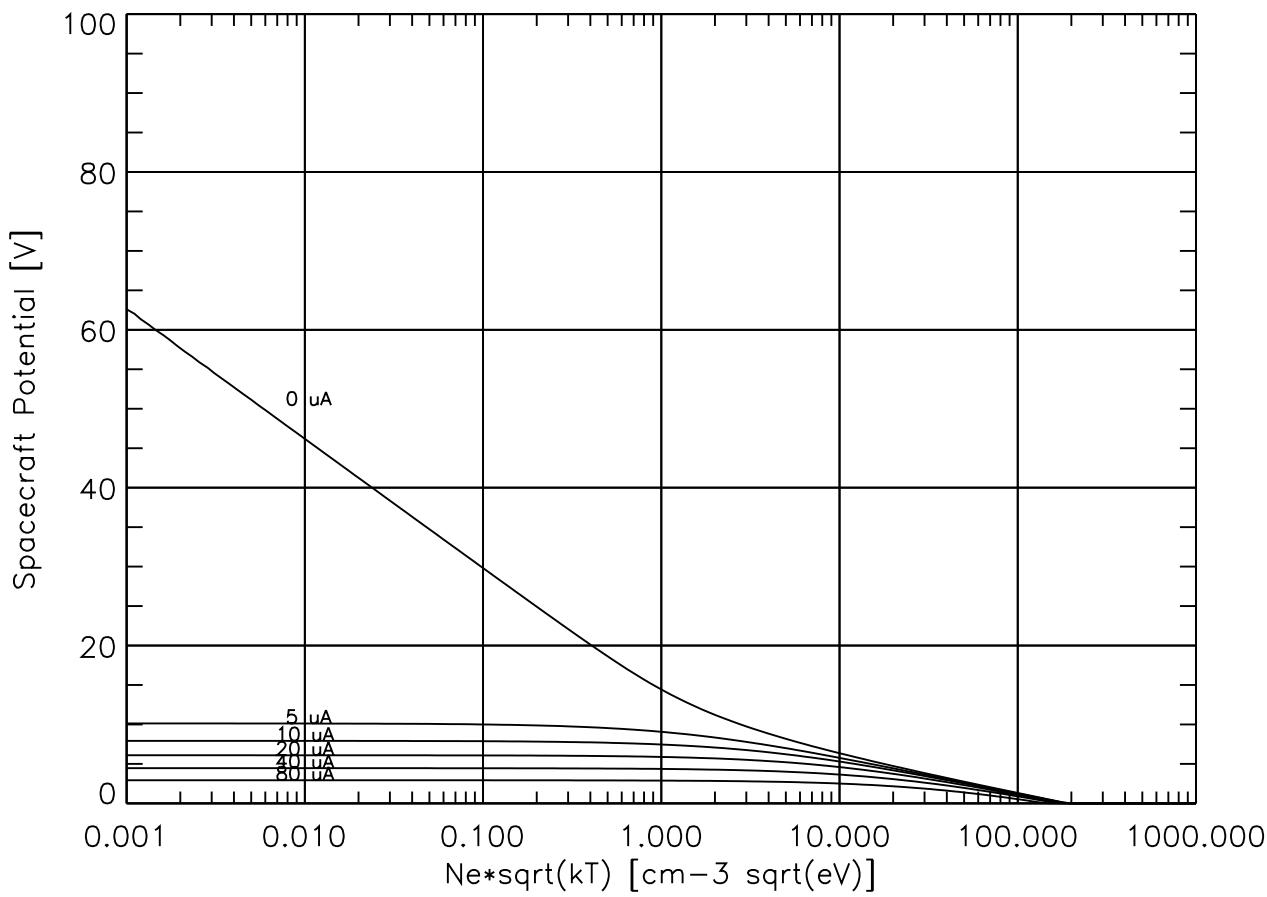

Fig. 1. Effect of an ion beam from 0 to $80 \mu \mathrm{A}$ on the spacecraft potential of Cluster.

For Cluster with $A_{s}=3.9 \mathrm{~m}^{2}$ and at $V_{s}=10 \mathrm{~V}$, the photoemission current flowing into space, according to Eq. (5), is $I_{p}=j_{p} \cdot V_{s}=5.2 \mu \mathrm{A}$. Hence, the equilibrium potential will settle at $V_{s}=10 \mathrm{~V}$ when the current from the ambient plasma, according to Eq. (3), exactly balances this current. A Maxwellian plasma with $100 \mathrm{eV}$ would achieve this at a density of $n_{e} \approx 1 \mathrm{~cm}^{-3}$.

In order to maintain a potential $\leq 10 \mathrm{~V}$ for a more tenuous plasma, an additional current has to be introduced into the system: a beam of ions at energies of 5 to $9 \mathrm{keV}$, as in the present instrument, can provide this constant independently of any small potential drop in the spacecraft sheath. The curve labelled " $0 \mu \mathrm{A}$ " in Fig. 1 shows the floating potential of a Cluster spacecraft over the quantity $\left(n \sqrt{k T_{e}}\right)$ based on Eqs. (3) and (5) and, therefore, is only valid for quiet conditions, i.e. no substorm-type conditions. By normalising the abscissa, the temperature variations of the electrons have been eliminated apart from corrections due to the term $\left(1+V_{s} / V_{e}\right)$ of Eq. (2). The dependence of the spacecraft potential on the plasma temperature is small. This has been shown by Escoubet et al. (1997) for ISEE-1 data. Figure 1 confirms the experimental results that the uncontrolled spacecraft potential may approach $+100 \mathrm{~V}$ in the magnetospheric lobes. Furthermore, it shows the stabilising effect of ion currents added to the system, even if the total ion current is well below the total photoemission current of the spacecraft. The figure also shows that the spacecraft potential control is most effective at low plasma density.

By doubling the ion current, the spacecraft potential is reduced by $\approx 2 \mathrm{~V}$. The optimum ion current results from a trade-off between several points:
- Particle measurements already increase considerably when the potential stays below $10 \mathrm{~V}$ and remains constant. An automated moment calculation on board can easily be programmed to calculate only when energies exceed $>10 \mathrm{~V}$. With spacecraft potential control, photoelectrons above this energy can be neglected, and the remaining errors in the calculation of the moments are small.

- A completely flat potential distribution across the spacecraft sheath cannot be enforced in the presence of space charges. Even if the potential of the spacecraft with respect to the plasma, which is measured at a large distance by the probes at the end of wire booms (tip-to-tip distance for Cluster: $88 \mathrm{~m}$ ), is known with high accuracy (the remaining uncertainty refers to the potential between the probe and the plasma), there is no measurement of the potential as a function of distance from the spacecraft except for a few measurement points during the wire boom release in the commissioning phase. Hence, the radial potential distribution remains a matter of theory. Complete, numerical 3D models for the conditions of Cluster are not yet available. An analytical study by Zhao et al. (1996), based on measurements on board Geotail, has limited the height of a potential barrier around a spacecraft with an ion beam for spacecraft potential control to $<2 \mathrm{~V}$.

- The electrical power consumed by the instrument increases linearly with the ion current.

- The lifetime of the ion sources decreases in proportion with the current. 


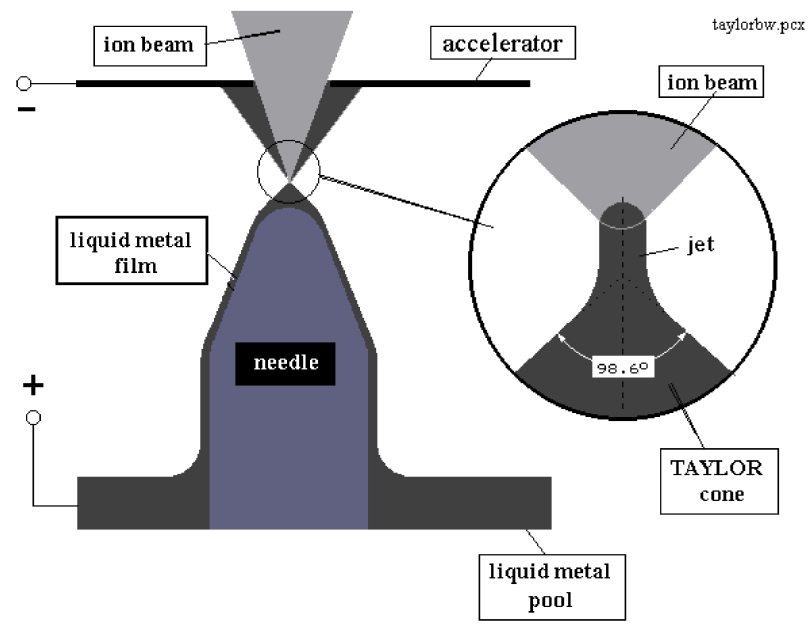

Fig. 2. Schematic plot of the principle of a needle type liquid metal ion source.

- The maximum current capability of the instrument drives the mass resources.

Based on these considerations, one can determine the optimum ion current, which will most likely lie in the range between 5 and $50 \mu \mathrm{A}$ for a Cluster spacecraft.

\section{Implementation for the Cluster mission}

\subsection{The ion emitters}

The ions are emitted by a "solid needle" type of Liquid Metal Ion Sources (LMIS), using indium as a charge material. A solid tungsten needle with a tip radius between 2 and $5 \mu \mathrm{m}$ is mounted in a heated reservoir with the molten charge material. The needle is wetted by an indium film. When a potential of 5 to $9 \mathrm{kV}$ is applied between the needle and an extractor electrode, the electrostatic stress at the tip of the needle acts against the surface tension forces of the liquid and pulls the liquid metal towards the extractor electrode. The equilibrium configuration assumed by the liquid surface is that of a Taylor cone (Taylor, 1964) with a total tip angle of $98.6^{\circ}$. The apex of the Taylor cone, in practice, reaches a diameter of 1 to $5 \mathrm{~nm}$ (Kingham and Swanson, 1984). Due to the small radius of curvature at the tip apex, the local electric field reaches values of the order of volts per nanometre, which is sufficient for field ion emission. A broad ion beam is formed (Fig. 2). The ion sources operate most efficiently in the current range from 10 to $30 \mu \mathrm{A}$, but higher currents are supported for a limited time.

Liquid Metal Ion Sources for spacecraft potential control have been described before for the respective instruments on board Geotail (Schmidt et al., 1993) and Cluster-I (Riedler et al., 1997). The basic principle (see, e.g. Mahoney et al., 1969) has undergone a major redesign to qualify the sources for space use (see Fehringer et al., 1997). For this instrument, indium (stable isotopes with $115 \mathrm{amu}$ and 113 amu to 95.7\% and $4.3 \%$, respectively) has been chosen as the ion-source charge material due to its low vapour pressure, which prevents the contamination of the source insulators and ambient spacecraft surfaces. On the other hand, the melting point at $156.6^{\circ} \mathrm{C}$ is high enough to prevent the melting of an unheated source charge. The current-voltage diagram of the LMIS shows a typical slope of 0.5 to $1.0 \mu \mathrm{A}$ per $10 \mathrm{~V}$ increase in the extraction voltage. The energy spread and the composition are important properties of the ion beam. Rüdenauer et al. (1987) showed in the laboratory that the beam consists of $>90 \%$ single-charged $\mathrm{In}^{+}$with minor fractions of doubleand triple-charged ions and single-charged indium clusters. The average charge number per emitted charged indium particle is 0.98 , and the mass efficiency, i.e. the fraction of the total mass taken by single-charged ions, at $10 \mu \mathrm{A}$ is about $80 \%$. The energy spectrum of the main $\mathrm{In}^{+}$contribution is composed of a quasi-Gaussian component centred a few volts below the electric potential of the tip, and of a lower energy tail extending more than $1 \mathrm{keV}$ below the centre width. The emitted $\mathrm{In}^{+}$ion current shows some broadening of the energy spectrum with increasing currents at the extraction electrode. At an emission current of $10 \mu \mathrm{A}$, the energy width is $150 \mathrm{eV}$, but a low-intensity, low-energy tail down to more than $500 \mathrm{eV}$ below nominal beam energy can be expected. The size of the reservoir ( $250 \mathrm{mg}$ for Cluster) allows for up to 4000 hours of nominal operating time at a $10 \mu \mathrm{A}$ emission current for a single emitter. Figure 3 shows a single ion emitter with its heater element. The indium reservoir and the needle are kept at high voltage. The emitters are individually and indirectly heated by a Pt100 wire resistor embedded in a ceramic insulator tube. This scheme enables the source to be heated from a grounded power supply, with the tip itself remaining a high voltage. The mass of an emitter is $1.2 \mathrm{~g}$ including the heater.

\subsection{The ion emitter modules}

In order to extend the operating time of the instrument and to provide additional redundancy, eight emitters were combined into one instrument, grouped into two so-called emitter modules powered by separate high voltage supplies. One module holds four individual ion emitters, which are operated one at a time. The individual emitters are embedded in porous ceramic with extremely low heat conduction $\left(<5 \times 10^{-4} \mathrm{~W} \mathrm{~K}^{-1} \mathrm{~cm}^{-1}\right)$. In this way, the typical power consumption of the heater can be kept at $0.5 \mathrm{~W}$. With 4000 hours of nominal operating time for a single emitter, two of them are more than sufficient to achieve the design goal of 5000 hours per module, which is based on a two-year mission with $\approx 50 \%$ operational coverage. The other emitters serve as a back-up.

All emitters have a common extraction and focusing lens arrangement with individual openings for each tip. It consists of a grounded extractor electrode, a focusing electrode at beam potential and a second ground electrode. These three electrodes constitute unipotential lenses for individual tips with the tip apex located in one focal point. The divergent 


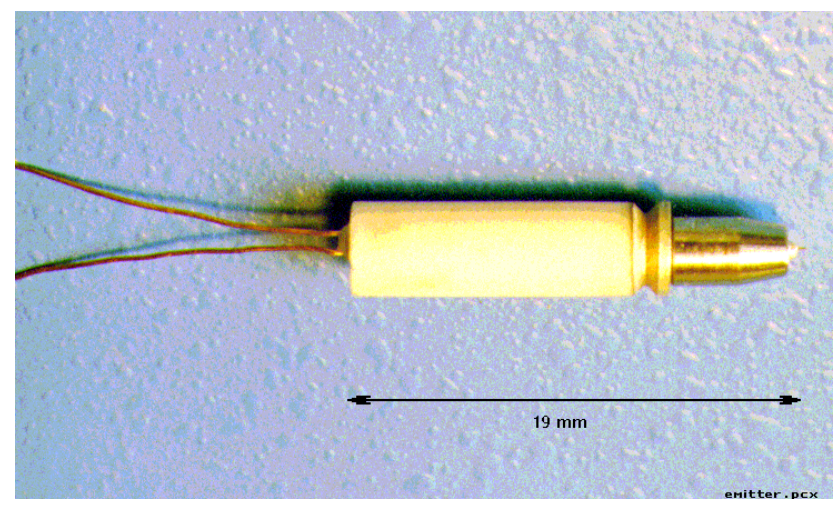

Fig. 3. Photograph of an indium ion emitter. The reservoir at the right is heated by the heater element at the left. The total length is $19 \mathrm{~mm}$.

ion beam (opening angle $\approx 90^{\circ}$ ) emitted from the tip is focused by this lens into a nominally parallel beam. The cold secondary side of the high-voltage supply is connected to the extraction and outer electrodes of the focusing lens, so that no additional power supply or voltage divider is required for beam focusing. Since the beam shaping and focusing optics are purely electrostatic, the lens properties and the beam shape remain unchanged if the tip voltage (identical to focusing voltage) changes.

Metal tubes around the heater elements protect the heaters and their power supply, which is connected to the ground by high-voltage strokes. With this grounding scheme, all possible paths for high-voltage discharges are confined within the high-voltage loop. Special attention has also been given to minimise sputtering from one individual emitter to another, and from an emitter to the isolators holding the electrodes. No ion can reach one of these surfaces without at least one reflection.

In order to avoid oxidation, the indium in the LMIS should never be exposed to air or water vapour. An almost hermetically closed volume has been designed (leak rate $\approx 8 \times 10^{-8}$ ) in which the emitters can be stored in a protective gaseous atmosphere. It is opened after launch by a pyrotechnic piston actuator which pushes away a hook that holds the springloaded cover plate in its locking position.

Due to the small volume of gas and the inevitable leakage, the initial internal overpressure of 0.2 bar would disappear within about one year during storage on the ground and cause air to enter from outside, thus contaminating the indium. For the initial deliveries, the flight units were therefore equipped with dummy emitter modules to be used during most of the test activities before launch. These dummies were replaced by the real emitter modules in the late exchange period before the spacecraft were shipped to the launch site.

\subsection{Beam current and extractor current}

In an ideal ion source, all generated ions would leave into space. This current loop is closed via the spacecraft surface by the ambient plasma and is called the ion current or beam current. With an increasing ion current, less photoelectrons or plasma electrons, respectively, can return to or arrive at the surface.

The total current is understood as the total current delivered by the high-voltage supply to the emitter. This current includes the beam current and internal loss currents (e.g. the current to the extraction and beam-focusing electrodes), and is therefore always larger than the beam current. For small to medium total currents $(<20 \mu \mathrm{A})$, the loss currents typically remain below $10 \%$, but the percentage may increase for higher currents.

\subsection{Overall configuration}

The ASPOC instrument is a single unit consisting of an electronics box and two cylindrical ion-emitter modules. Figure 4 shows the instrument with its two emitter modules mounted on top of the electronics box. The thermal blanket of the spacecraft is attached to the plate on top of the unit. The viewing direction is parallel to the spin axis to avoid spin modulation of the currents. The wall thickness of the box is $0.8 \mathrm{~mm}$. It carries four printed-circuit boards and a motherboard. The electronic components have been selected, in general, to withstand the predicted dose of ionising radiation of $\approx 15 \mathrm{krad}(\mathrm{Si})$ at the wall thickness of $0.8 \mathrm{~mm}$. Additional spot shielding has been applied to a few less hard components.

\subsection{Electronics}

The instrument uses an 80C85 microprocessor (1) to operate and control the ion-emitting system (high voltage and heater power), (2) to perform the start-up procedure of the emitters, and (3) to serve the interfaces to the onboard data-handling and telecommand units, and to the electricfield instrument (EFW) and low-energy electron spectrometer (PEACE) which provide spacecraft potential data in real time. Due to the low data rate (108 bit/s), both housekeeping and science data are transmitted through the housekeeping channel. Complete status information is given within two housekeeping data frames $(\approx 10.3 \mathrm{~s})$.

The flight software is downloaded from PROM into CMOS RAM when the instrument is turned on. A large part of the logic circuits that are not interfacing the spacecraft is contained in a programmable gate array (FPGA). The DPU and the spacecraft interface logic cover two printed-circuit boards. The DPU has a watchdog timer. If a counter is not reset regularly by the program running in the DPU, it will perform a full reset of the DPU and a reload of the programme from the PROM into the RAM after $8 \mathrm{~s}$.

The DC converter and the high-voltage unit each take up one printed-circuit board. The DC converter provides three fixed voltages $(+5 \mathrm{~V},+13.5 \mathrm{~V},-5 \mathrm{~V})$ and a variable output for the heater elements in the emitters. The high-voltage unit can power one of the two emitter modules at a time in voltage- or current-controlled modes. The voltage-controlled 


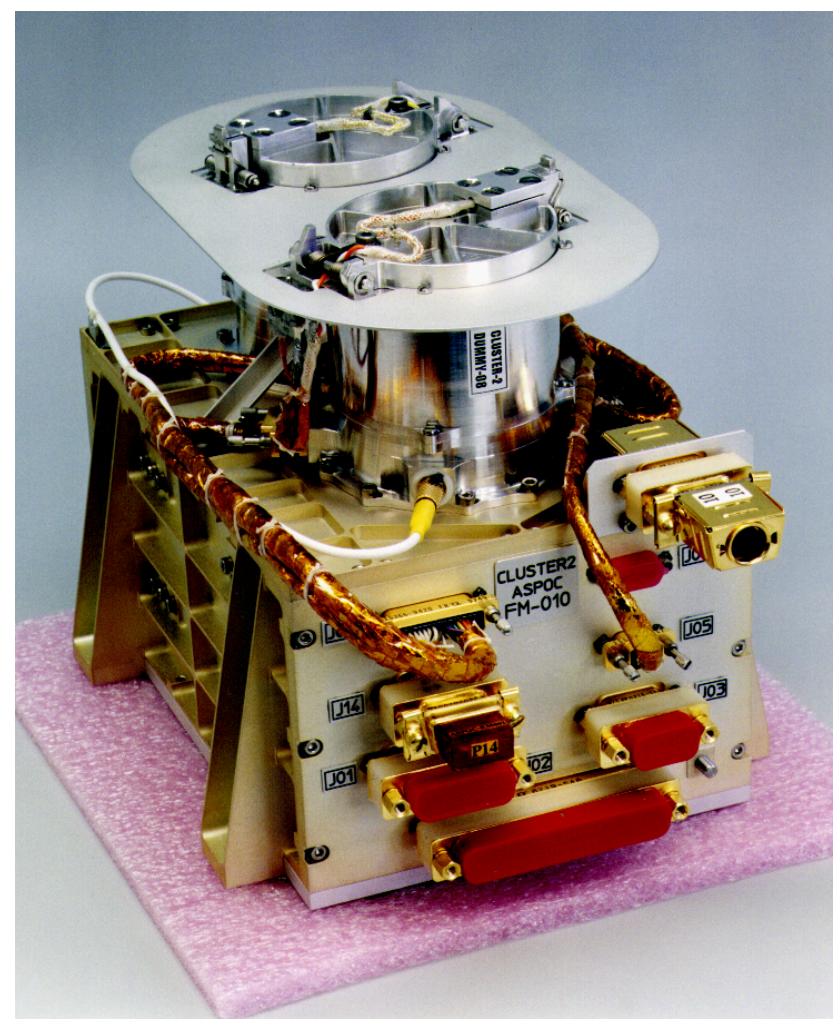

Fig. 4. Photo of the instrument.

mode is used during start-up of an emitter, before any ion current is drawn. As soon as ion emission starts, the supply is switched into current-controlled mode to ensure a constant current. The voltage and hence, the energy of the ions is of secondary importance. The analogue monitors of the high voltage, the total output current at high voltage and the effective ion-beam current are provided. The latter measurement necessitates a special grounding concept for the emitter supply unit. The power consumption consists of an almost constant component of $\approx 1 \mathrm{~W}$ for the DPU and the heating of one emitter filament $(\approx 0.8 \mathrm{~W})$, and a variable part which is largely proportional to the emitted ion current. While $3 \mathrm{~W}$ peak primary power can be reached by design, the maximum power reached during nominal operations is $2.7 \mathrm{~W}$, and an average value of $2.4 \mathrm{~W}$ primary power complies with the requirements on the ion current for spacecraft potential control in the expected plasma environment.

Redundancy is achieved by two separate high voltage cascades. , There are separate high voltage cascades including the secondary side of the transformer, and the current and voltage monitors for each module, whereas the digital processing unit and the low voltage side of the high voltage supply are not redundant. The switching of high voltage between modules is done by a latching relay at the primary side.

\subsection{Changes since Cluster-I}

Since the original design of the ion emitters and the emitter modules for Cluster-I and Geotail, some flight experience
Table 1. Instrument data summary

\begin{tabular}{ll}
\hline Quantity & Value \\
\hline Mass & \\
Electronics box & $1460 \mathrm{~g}$ \\
2 emitter modules with covers & $360 \mathrm{~g}$ \\
Harness & $50 \mathrm{~g}$ \\
Flange for thermal blanket & $30 \mathrm{~g}$ \\
Total & $1900 \mathrm{~g}$ \\
\hline Size & \\
Electronics box & $187 \times 157 \times 95 \mathrm{~mm}$ \\
Emitter modules, closed & $60 \mathrm{~mm}$ dia. $\times 75 \mathrm{~mm}$ \\
Overall & $187 \times 157 \times 170 \mathrm{~mm}$ \\
\hline Power & \\
Average power & $2.4 \mathrm{~W}$ \\
Peak power & $2.7 \mathrm{~W}$ \\
\hline Telemetry rate & $108 \mathrm{bit} / \mathrm{s}$ \\
\hline Design lifetime & 10000 hours at $10 \mu \mathrm{A}$ \\
\hline Beam characteristics & \\
Species & In ${ }^{+}$ \\
Atomic mass & $113,115 \mathrm{amu}$ \\
Energy & $\approx 5$ to $9 \mathrm{keV}$ \\
Current & max. $65 \mu \mathrm{A}$, design: $10 \mu \mathrm{A}$ \\
Opening angle (half maximum) & $\pm 15^{\circ}$ \\
Direction & along spin axis \\
\hline &
\end{tabular}

with Geotail and Equator-S has become available. It turns out that the thickness of the indium film covering the emitter needles is a very sensible parameter. A thicker film enhances the capability to emit large currents at moderately higher operating voltage, but it increases the average ignition and operating voltage. The production process of the emitters was improved to ensure small deviations from the optimum thickness.

The laboratory test set-up was changed to allow for further shielding of emitters against backsputtering from the walls of the vacuum chamber.

A feature to limit the high-voltage applied to the emitter when operating in constant current mode was added to the instrument software. When the voltage threshold is reached, the emitter is either turned off or a cleaning cycle is executed. With this safety feature in place, the high-voltage capability of the supply was set to $9.3 \mathrm{kV}$.

\subsection{Instrument data summary}

The main instrument data are summarised in Table 1.

\section{Operating modes}

\subsection{Constant current mode}

The basic operating mode of ASPOC involves setting the total emitter supply current to some predetermined value based 


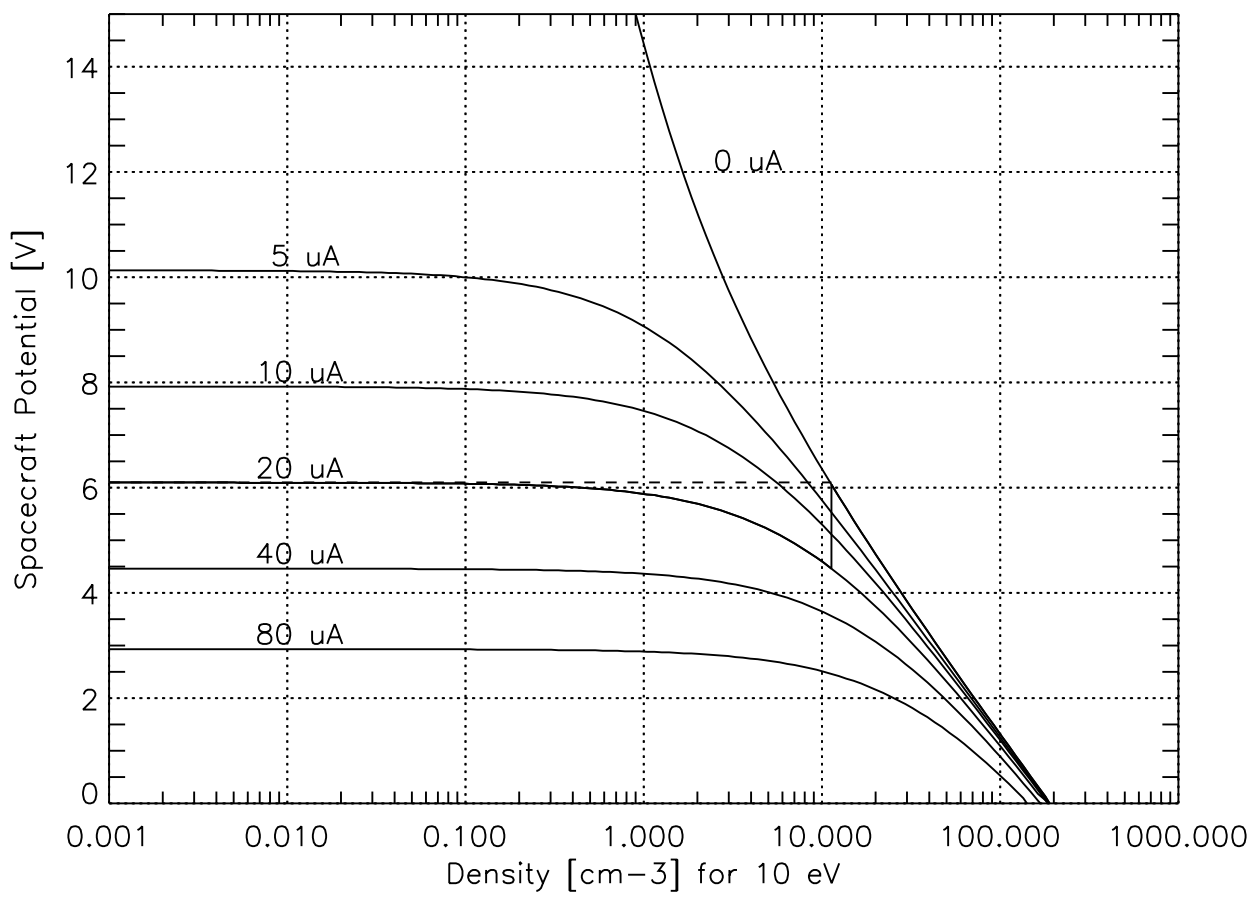

Fig. 5. Spacecraft potential control in constant current mode at $20 \mu \mathrm{A}$ (bold line) and in feedback mode (dashed line).

on the spacecraft current-voltage characteristics and experience gained in the mission. Since the loss current inside the instrument to the extractor electrode can normally be neglected, the constant total current mode at the same time produces a constant ion beam current. The value of the current can be set by time-tagged commands to vary according to the expected plasma environment along the orbit. At the same time, the current level must be sufficiently low to ensure that the spacecraft potential does not become negative. Experience during the first seven months after launch proves theoretical expectations that negative charging events are unlikely on the Cluster orbit. In fact, no significant negative charging event has been observed so far. This constant total current mode has been chosen as the baseline mode for the Cluster mission due to its robustness combined with sufficient scientific performance.

There is another standalone mode that maintains a constant current of the emitted ion beam rather than the total current fed into the ion emitter. This mode does not provide any significant improvement over the previous mode, but includes the risk that high total currents are drawn from an emitter which produces an abnormally high internal current to the extractor electrode. While such cases are unlikely, they might, if they occur, significantly reduce the total lifetime of this emitter. Therefore, this mode has not been selected as a the baseline mode.

\subsection{Feedback mode}

In a more complex operating mode, a measurement of the spacecraft potential is supplied to ASPOC by either the electric-field experiment (EFW) or the electron analyser
(PEACE), and this information is used to adjust the emission current so that the spacecraft potential is kept at a desired value in a closed loop scheme. This mode is called feedback mode.

Probes 1 and 2 of EFW are always operated in voltage mode to measure the electric field. EFW flight software calculates the mean value of the unfiltered spacecraft potential raw data measured between the spacecraft body and probes 1 and 2, respectively. The resulting quantity $V_{s c}=-\left(V_{1}+V_{2}\right) / 2$ is sampled every second and sent to the Digital Wave Processor (DWP) instrument, which combines it with operating mode information from the WHISPER sounder (Décréau et al., 1997) and transmits the product to ASPOC via a dedicated serial, the digital Inter-Experiment Link (IEL) interface.

There is an alternative feedback mode using estimates of the spacecraft potential calculated from the low energy portion of the electron spectrum by the onboard processor of the instrument PEACE.

Figure 5 illustrates the slight improvement of the feedback mode (dashed line) over the constant current mode (bold line). The figure shows the spacecraft potential over the quantity $\left(n \sqrt{k T_{e}}\right)$, as in Fig. 1, but here in Fig. 5 the abscissa is labeled according to density, assuming an electron temperature of $10 \mathrm{eV}$. In constant current mode that is set to $20 \mu \mathrm{A}$, the potential would be limited to $6 \mathrm{~V}$ at low densities and decrease for densities higher than $\approx 0.3 \mathrm{~cm}^{-3}$. In this figure it is assumed that at $n>10 \mathrm{~cm}^{-3}$, the ion emitter would be turned off according to a time-tagged command. The resulting small variation in the potential in the transition region between low and high densities ( $n \approx 0.3$ to $n \approx 10 \mathrm{~cm}^{-3}$ ) can 
Table 2. ASPOC mode summary

\begin{tabular}{llll}
\hline Mode & Description & Ion current & Typical duration \\
\hline $\begin{array}{l}\text { Standby } \\
\text { Start-up }\end{array}$ & $\begin{array}{l}\text { Passive mode } \\
\text { Warm up, then ignite ion emitter }\end{array}$ & $\begin{array}{l}\text { none } \\
\text { zero, ending with short }(<1 \mathrm{~s}) \\
\text { peak }(I<50 \mu \mathrm{A})\end{array}$ & $\begin{array}{l}\text { No limit } \\
13 \text { to } 15 \text { min }\end{array}$ \\
Feedback & $\begin{array}{l}\text { Control loop with spacecraft potential data from } \\
\text { EFW or estimates from PEACE }\end{array}$ & Variable & No limit \\
Constant Current & Emission independent of spacecraft potential & Constant & No limit \\
Calibration & Measure current-voltage characteristics & Step function & 2 to 10 min \\
Active experiments & Ion beam experiments & Step function & No limit \\
\hline
\end{tabular}

be eliminated by operating the instrument in feedback mode (dashed line), where the ion current is automatically set to values between 0 and $20 \mu \mathrm{A}$ in order to maintain a potential of $6 \mathrm{~V}$. In the high density regime, where the spacecraft potential eventually turns negative, the ion beam is turned off in both operating modes, automatically in feedback mode and by a time-tagged command based on predicted densities in constant current mode. Such conditions are, however, rather exceptional for the Cluster orbit with a $4 \times 19.6$ Earth radii geocentric distance. The active spacecraft potential control loop has been successfully tested during the commissioning phase (see Sect. 5.3).

\subsection{Test and commissioning mode}

For calibration and "active experiment" purposes, a so-called Test and Commissioning Mode has been defined. Its main objective lies in the measurement of the current-voltage characteristics of the spacecraft at the beginning and in regular intervals throughout the mission, in order to look for changes in the photoemission properties of the surface. In this mode, the ion current is stepped over a wide range, and the spacecraft potential is measured simultaneously by EFW. The length of each step is 8 or $16 \mathrm{~s}$, the equivalent of about 2 to 4 spin periods.

\subsection{Hot standby mode}

Occasionally the ion-beam emission may have to be turned off in a pre-planned manner during time intervals varying from a few minutes up to fractions of hours, depending on the expected ambient plasma conditions or due to operational requirements, for example, during the interference test campaign, when this mode turned out to be very useful. In Hot Standby mode, the ion emitter is kept at elevated temperature and the indium remains liquid in order to ensure immediate re-start capability. As soon as the high voltage is ramped up, the emitter ignites again at almost the same voltage as during the previous operation.

\subsection{Standby mode}

In standby mode, the instrument remains completely passive: the high voltage, the ion-beam emission, and the heater filaments of the emitters are turned off. The instrument processor only serves the interfaces to the spacecraft and the InterExperiment Link, and produces housekeeping data. Standby mode is the power-on mode and also the contingency mode in case of problems with the ion-beam emission. The instrument does not have permanent memory. Standby mode is, therefore, useful to keep parameters in internal memory, which otherwise would have to be uplinked again after power-off. Standby mode is the default mode between data-acquisition intervals within one orbit. The default mode during perigee passes through the radiation belts is OFF.

\subsection{Start-up of emitters}

The indium reservoir of an emitter has to be heated before high voltage can be applied. Depending on the ambient temperature and the thermal coupling of an individual emitter, it takes 13 to 15 minutes to reach the operational temperature of an emitter. The gradual temperature increase and the turn-on of high voltage is performed autonomously by the instrument after one of the emitters has been selected and one of the active operating modes has been commanded. Immediately after the onset of ion emission $(I>2.2 \mu \mathrm{A}$, the instrument switches into the commanded operating mode. Due to limited resources, only one emitter can be heated at a time. Whenever a change in the active emitter is required, the previous emitter has to be turned off before the start-up of the new emitter can occur.

\subsection{Cleaning of emitters}

As eight emitters are present in each instrument, it is obviously necessary to change the working emitter from time to time. Four emitters are combined in a module with common electrodes, which poses a small risk of cross-contamination between emitters. Material sputtered from the lens system of the active emitter may accumulate on the passive emitters and 
thereby increase the ignition voltage of the latter. Conditions generally return to normal after some minutes of operation due to a self-cleaning effect of the active emitter. This selfcleaning capability increases with the applied current. This can be used as a precautionary measure against the possible contamination of an emitter. The signatures are a slow increase in the operating voltage, reflecting the higher flow impedance of the liquid indium. The instrument software can be set to monitor the operating voltage and to trigger a short high-current peak ( 20 to $60 \mathrm{~s}, 50$ to $80 \mu \mathrm{A}$ ) when the voltage exceeds a threshold. Alternatively, such "cleaning cycles" may be performed by explicit time-tagged commands and even as a preventive measure without any measurable preceding change in voltage.

While the start-up of emitters at the beginning of data acquisition and during the switch-over to another emitter cause short interruptions in the spacecraft potential control, occasional "cleanings" would drive the potential to slightly lower values, but the currents involved $(<80 \mu \mathrm{A})$ are not sufficient to drive the potential to negative values (see Fig. 1).

\subsection{Technical mode}

Finally, a technical mode is available to perform low-level commanding for basic inspection of the instrument. A summary of operational modes is given in Table 2.

\subsection{Contingencies}

Possible failure conditions from external sources (e.g. an unexpected absence of spacecraft potential data in feedback mode) or technical problems with the instrument (e.g. failure of an emitter) may be grouped into three categories:

1. Failure of an ion emitter,

2. Failure of the active inter-experiment link from EFW/DWP or PEACE,

3. Disturbances by the WHISPER instrument in its active mode.

Case 1 is detected autonomously by the instrument, which switches into the safe standby mode. Thereafter, contingency actions will be taken from the ground. Case 2 is covered by the instrument's capability to switch into a back-up operational mode which does not rely on the inter-experiment link. If any unexpected interruption of the spacecraft potential data flow occurs while ASPOC is in feedback mode, the ion emission is kept at the last value for a few spin periods before the current is either turned off or set to constant value (standby or stand-alone mode).

As for case 3, it turns out that the WHISPER instrument in its active sounding modes changes the instantaneous measurement of the spacecraft potential. In its active mode as a relaxation sounder, the instrument WHISPER emits pulses from the wire boom antennae with amplitudes up to $200 \mathrm{~V}_{\mathrm{pp}}$. These disturbances are successfully removed in the high resolution data of EFW, but the data received by ASPOC on the
Table 3. Selection criteria for ion emitters

\begin{tabular}{ll}
\hline Ignition voltage of the emitter & $<8.3 \mathrm{kV}$ \\
Operating voltage of the emitter & $<8.0 \mathrm{kV}$ \\
Current efficiency & $>90 \%$ \\
Power versus temperature char- & $0.45 \ldots 0.6 \mathrm{~W}$ at $\mathrm{T} \approx 300^{\circ} \mathrm{C}$ \\
acteristics of the heater & \\
\hline
\end{tabular}

IEL are unfiltered raw data samples of the potential, which contain some disturbances.

\section{First results}

\subsection{Performance of emitters}

During the commissioning phase between launch and 21 December 2000, the ion emitters in the four instruments have been characterised, and the emitters to be used during nominal operations were selected. Table 3 lists the key parameters with the selection criteria for the nominal mission.

A total of 87 start-ups of emitters was carried out in the commissioning phase, resulting in a ranking of emitters for each of the spacecraft 2,3 , and 4 . Up to $180 \mathrm{~h}$ of operation time for a single emitter were achieved, including the first months of the nominal mission until 7 April 2001.

On 27 August 2000, on spacecraft 1, during the start-up of one of the emitters, a discharge occurred somewhere in the high-voltage parts, therby damaging a multiplexer in the emitter monitor circuit. The very unfortunate side effect of this event was that further high-voltage operations of this instrument became impossible.

\subsection{Effect on spacecraft potential}

Figure 6 shows the spacecraft potential during commissioning operations of spacecraft 2 on 13 September 2000, in red. The spacecraft were located in the magnetotail at $\approx 23: 00 \mathrm{LT}$, moving in and out the plasmasheet. The spacecraft were separated by $\approx 1000 \mathrm{~km}$, primarily in longitude. In this time interval of about $3 \mathrm{~h}$, two different emitters were operated on spacecraft 2. For comparison, the uncontrolled potential of spacecraft 1 is shown in black.

From 20:03 to 21:05, emitter B2 was operated in constant total current mode. After one minute at $15 \mu \mathrm{A}$ immediately after start-up, the ion beam current varied slightly between 10 and $11 \mu \mathrm{A}$. The variation was due to minor changes in the efficiency. The dramatic reduction of the potential from values $>20 \mathrm{~V}$ before emitter was turned on to $7-8 \mathrm{~V}$ is obvious. During this interval, the potential on spacecraft 1 peaks at $40 \mathrm{~V}$. Since the two curves for the potential follow each other closely when ASPOC is OFF, one can assume that the potential of spacecraft 2 would have reached $40 \mathrm{~V}$ as well. The large fluctuations in the uncontrolled potential are reduced to variations of $<1 \mathrm{~V}$ on spacecraft 2 . 


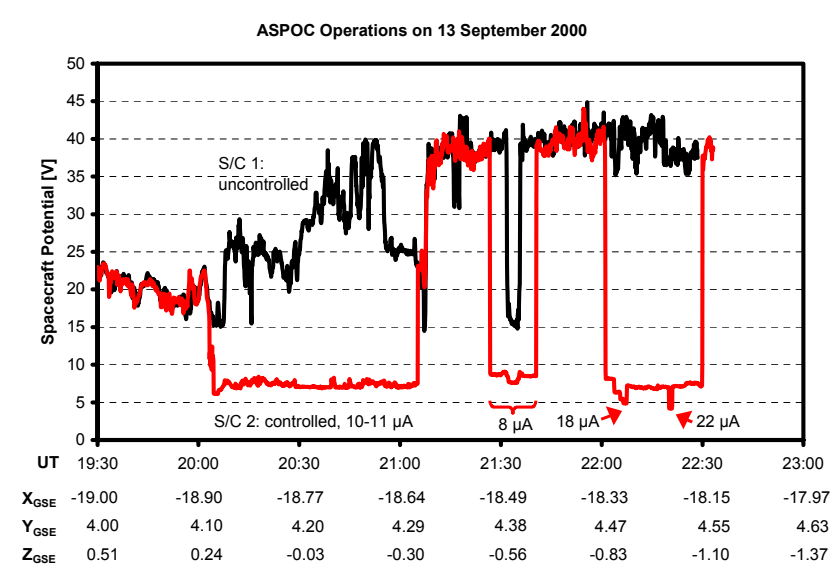

Fig. 6. ASPOC operation in constant current mode during commissioning of spacecraft 2 on 13 September 2000. Positions of spacecraft 2 are given in Earth radii.

This stabilising effect on the potential is confirmed by the second operating interval from 21:27 to 21:40, using emitter $\mathrm{B} 3$ at $8 \mu \mathrm{A}$ ion current. The deep drop of the potential from 40 to $15 \mathrm{~V}$ on spacecraft 1 is attenuated to a variation from 8.7 to $7.6 \mathrm{~V}$.

The interval from 22:01 to 22:30, again with emitter B2 and $10 \mu \mathrm{A}$ is similar to the first one, but short excursions to higher ion currents of 18 and $20 \mu \mathrm{A}$, respectively, have been tested. With $22 \mu \mathrm{A}$, the spacecraft potential drops to $4.2 \mathrm{~V}$. The potential data in this plot are understood as the potential between the spacecraft body and the probes. In order to obtain the potential of the spacecraft with respect to the potential of the ambient plasma, the floating potential of the probes has to be added, which is typically $1 \mathrm{~V}$ or below.

The objective of the feedback mode is to remove even the small residual variations in the potential, similar to the one at about 21:35 on 13 September 2000. Figure 7 shows another example from the commissioning tests on 25 September 2000. During a series of tests, the ion current was kept constant in many individual current settings between 5 and $15 \mu \mathrm{A}$, shown with black symbols. Groups of points aligned in the vertical direction, e.g. at $4.5 \mu \mathrm{A}, 6 \mu \mathrm{A}$ and $12 \mu \mathrm{A}$, appear when the current was held over extended time intervals, while the ambient plasma conditions were changing, and - as a result - the spacecraft potential was changing accordingly. The red symbols refer to an interval of $11 \mathrm{~min}$ when the feedback mode with EFW was tested. The spacecraft potential was set to $9 \mathrm{~V}$, and the instrument processor autonomously adjusted the ion current in the range from 7 to $9 \mu \mathrm{A}$. As a result, the residual variation in the potential is reduced to $\pm 0.3 \mathrm{~V}$. A further reduction would have been possible by increasing the basic resolution of the onboard computation.

\subsection{Effect on low energy electron measurements}

The initial results of the spacecraft potential control on low energy electron measurements are described in detail by

\section{ASPOC Operations on 25 September 2000 10:35 - 16:42}

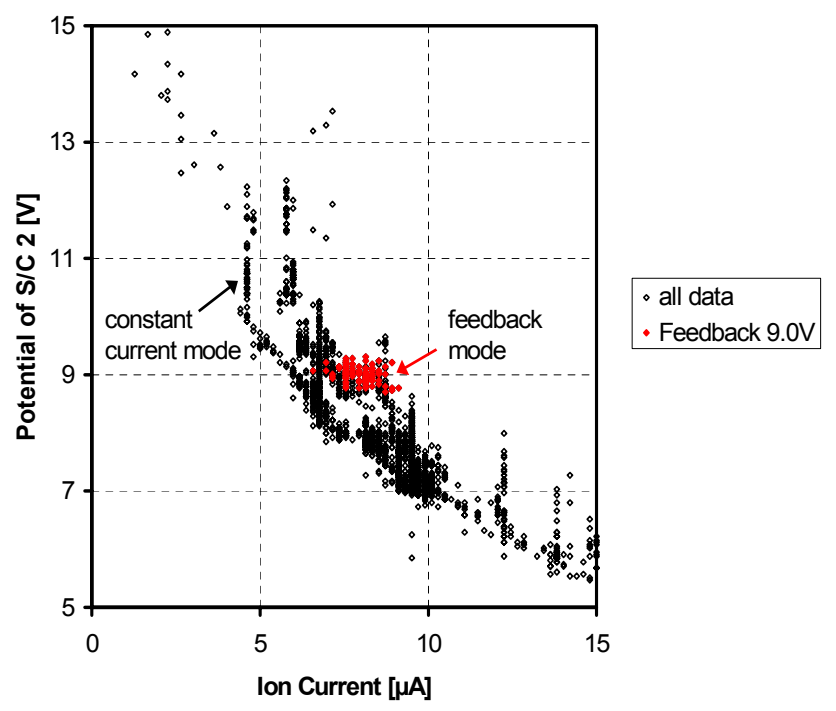

Fig. 7. ASPOC operation in constant current mode and feedback mode during commissioning of spacecraft 2 on 25 September 2000.

Szita et al. (2001, this issue). For completeness, their Fig. 4 is reproduced here as Fig. 8. It shows data taken by the LEEA sensor of PEACE with anode 11, which sees electrons arriving approximately along the spacecraft spin axis, from a direction opposite to the solar panels. Thus, the contamination by photoelectrons should be rather small. Nevertheless, the top panel, showing spacecraft 1 without potential control, and the other panels for spacecraft 2 to 4 before 02:27 and after $05: 13$ on 7 February 2001, show significant signatures of photoelectrons in the lower parts of the energy spectrograms. Between these times on spacecraft 2 to 4, the ASPOC ion beam was set to $10 \mu \mathrm{A}$, thereby reducing the spacecraft potential from the uncontrolled situation with $\approx 20 \mathrm{~V}$ to values between $\approx 8.5 \mathrm{~V}$ at the beginning of the interval and $\approx 6.5 \mathrm{~V}$ at the end. The residual variation is caused by an increasing trend in the total density, and possibly a simultaneous increase of the mean temperature. The high-energy tail of the photoelectrons returning to the sensor appearing as a green trace between $\approx 10$ and $\approx 40 \mathrm{eV}$, merges with ambient electron features in the $100 \mathrm{eV}$ range on board the uncontrolled spacecraft 1, whereas on spacecraft 2 to 4 , the natural features can be observed cleanly and with less modification of their energies when they pass the spacecraft sheath.

Figure 9 illustrates that the electron distribution measured at low energies is complex and requires further analysis. Each panel shows an energy-time spectrogram of count rates from a polar sector of $\approx 30^{\circ}$ resolution for a time interval of 5 spins $(20 \mathrm{~s})$. The energy scale is nearly logarithmic (step 8 is $\approx 5 \mathrm{eV}$, step 16 is $\approx 10 \mathrm{eV}$, step 24 is $\approx 20 \mathrm{eV}$, step 36 is $\approx 80 \mathrm{eV}$, step 40 is $\approx 130 \mathrm{eV}$ ). The top left panels show electrons arriving from the main engine; the lower right panel shows electrons arriving from the opposite direction; and the bottom left and top right panels show electrons trav- 

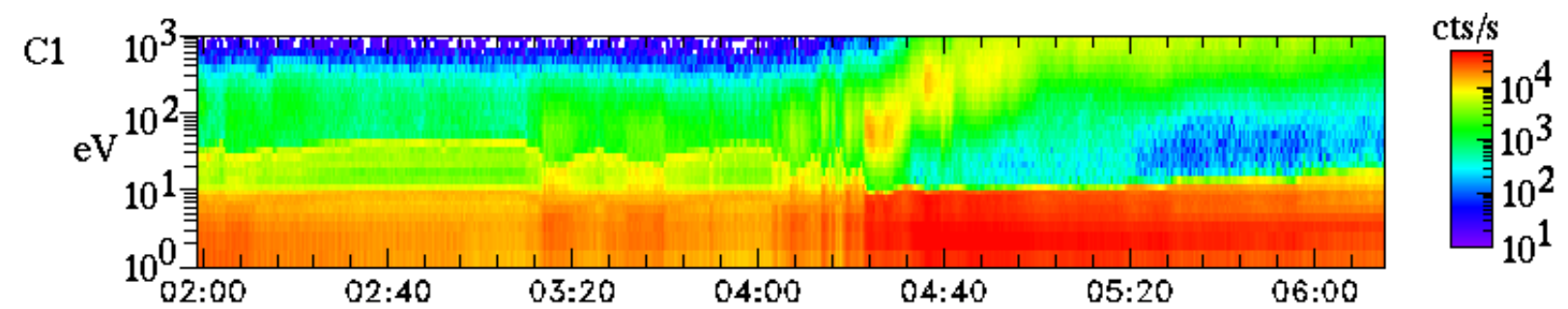

C2

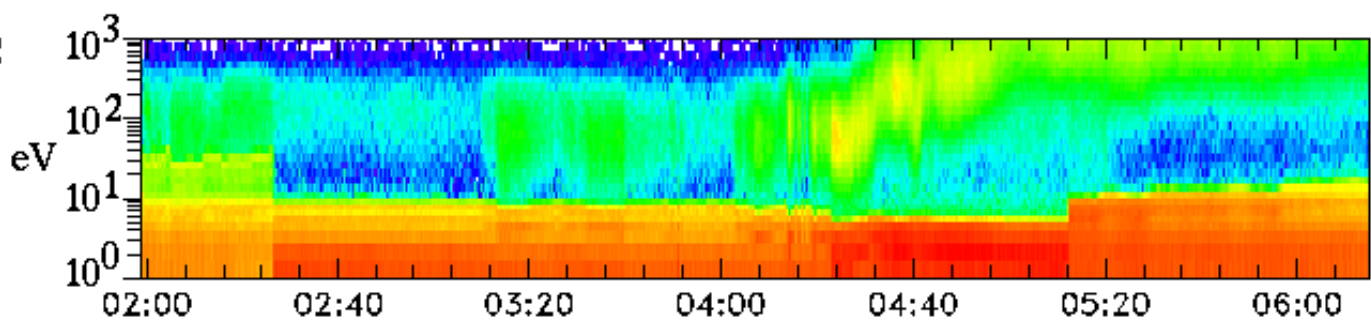

$\mathrm{cts} / \mathrm{s}$

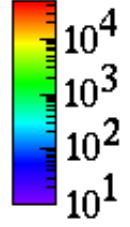

C3

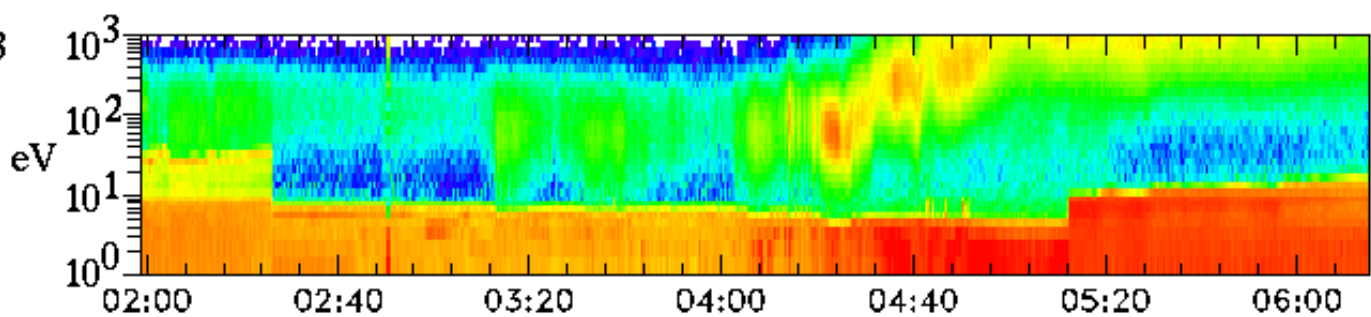

$\mathrm{cts} / \mathrm{s}$

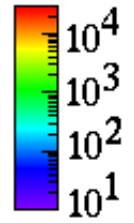

C4

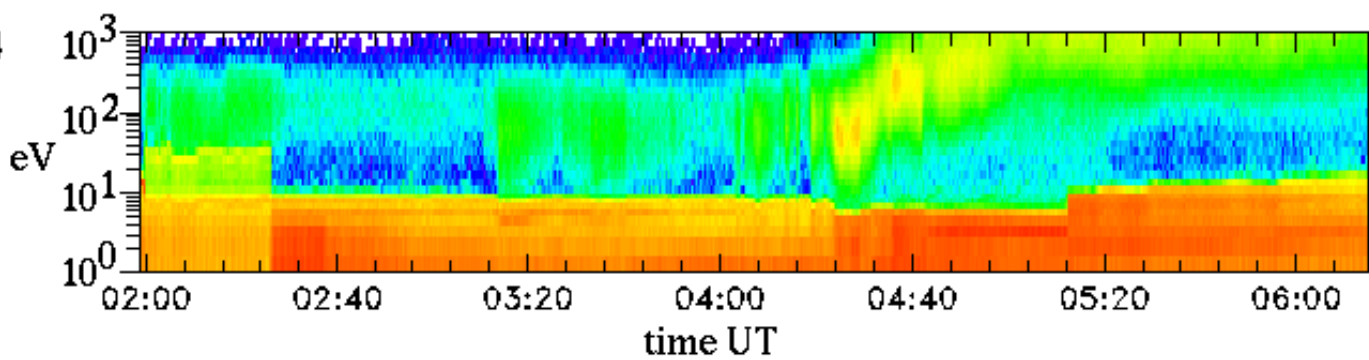

$\mathrm{cts} / \mathrm{s}$

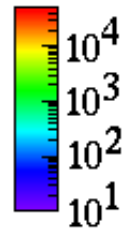

Fig. 8. Figure reproduced from Fig. 4 of Szita et al. (2001,this issue); data taken by the PEACE/LEEA in anode 11; for spacecraft 1 (top panel) to 4 (bottom panel); the ASPOC ion beam is active on spacecraft 2 to 4 between 02:27 and 05:13 on 7 February 2001.

elling near the spacecraft spin plane. The maximum count rates appear at the sunlit side.

The data have been taken during the interference campaign on 16 December 2000. During the first two spin periods, ASPOC is still emitting a $10 \mu \mathrm{A}$ ion beam. Electrons with an origin at the spacecraft are visible (green band) up to level 17 $(\approx 11 \mathrm{eV})$. Narrow vertical features occur when the sensor sees the Sun. The spacecraft-probe potential is $\approx 9 \mathrm{~V}$. When the ion beam is turned off, the potential jumps to $\approx 50 \mathrm{~V}$, and the spectrograms show features extending up to this energy.

\subsection{Effect on other measurements}

When ASPOC is active, the ion spectrometer CIS (Rème et al., 1997) can detect low energy ions which otherwise would be reflected in the spacecraft sheath. The count rates of major species $\mathrm{H}^{+}$and $\mathrm{O}^{+}$increase significantly. Features of minor species, such as $\mathrm{He}^{+}$and $\mathrm{He}^{++}$, may even disappear in the background noise as soon as ASPOC is turned off.

As expected, wave instruments, both in the magnetic and electric domains, do not see any effect of the ion beam or the modifications to the spacecraft sheath caused by ASPOC. A different situation is found with the electric field instrument (EFW, Gustafsson et al., 1997). Features of the ambient electric field may be attenuated in the measurements when ASPOC is active. The magnitude of the effect is highly variable and obviously dependent on the ambient plasma density.

\section{Discussion}

\subsection{Beneficial aspects and side effects}

The previous overview of initial ASPOC operations has demonstrated that the concept of spacecraft potential control using a high-energy ion beam works satisfactorily:

- The residual spacecraft potential follows very closely the expectations based on model calculations and previous experience, 


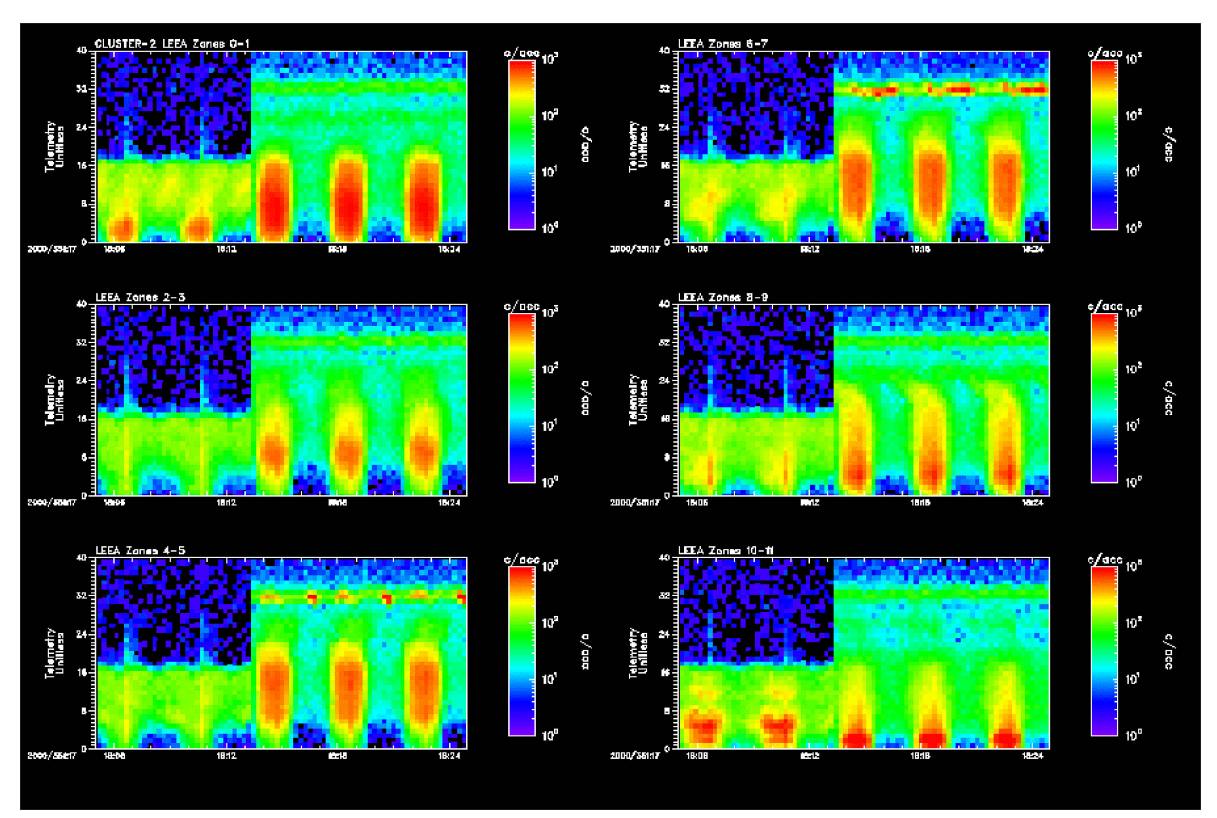

Fig. 9. Energy-time spectrograms of the PEACE/LEEA sensor over five spin periods on 16 December 2000 covering an ON-OFF transition of the ASPOC ion beam. The energy scale is quasi-logarithmic between $\approx 0 \mathrm{eV}$ to $\approx 130 \mathrm{eV}$. Panels are for 6 different polar angles.

- There are major beneficial effects on the low energy particle measurements of PEACE and CIS.

A large number of theoretically possible side effects is definitely absent, as anticipated when the instrument had been conceived. Riedler et al. (1997) list these non-effects.

The emission of a charged particle beam into a plasma is a potential source of electrostatic and electromagnetic noise, but a numerical simulation study (Schmidt et al., 1992) dealt with the plasma response to the emission of very weak ion beams and found that the beam must be very cold for an instability to be excited and only an adverse combination of parameters would lead to wave growth. In the lobes, where spacecraft potential control is most valuable, the injection only rarely occurs transverse to the magnetic field, and the plasma conditions have the highest threshold for wave growth.

Chemical contamination by the ion beam, for example, by:

- condensation of neutral indium in the vicinity of the ion emitter,

- a return to the spacecraft of $\mathrm{In}+$ ions after one or more gyrations,

- the interaction of the ion beam with spacecraft surfaces, could be ruled out for various reasons: the vapour pressure of indium is only $1 \times 10^{-15} \mathrm{mbar}$ at $250^{\circ} \mathrm{C}$ and the total surface from which indium evaporates is of the order of $1 \mathrm{~mm}^{2}$ for the active, hot emitter and about $9 \mathrm{~mm}^{2}$ for the surfaces at the environmental temperature. In addition, the measured mass efficiency sets an upper limit to the neutral indium emission of $3 \%$. The typical mean free path length for neutral collisions exceeds $10^{4} \mathrm{~m}$ if the pressure drops below $10^{-8}$ mbar.
Hence, collisions are extremely unlikely to occur. Photoionisation of neutral indium and the attraction of these ions by negatively charged, non-conductive and shadowed surfaces is negligible, since the photoionisation efficiency at $1 \mathrm{AU}$ is of the order of $10^{-7}$, and a particle density inferred from the indium partial pressure of $10^{-15}$ mbar at a nominal operating temperature of $10^{3} \mathrm{~m}^{-3}$ yields a negligible amount of $\mathrm{In}^{+}$to be produced in the neighbourhood of the spacecraft. Finally, the gyro radius of the ions at a typical energy of $6 \mathrm{keV}$ is huge; it lies between 120 and $12000 \mathrm{~km}$ for magnetic fields of 1000 and $10 \mathrm{nT}$, respectively. Since the beam opening angle is $\pm 15^{\circ}$, only a negligible number of ions may return to the spacecraft. For perpendicular injection at $B=10 \mathrm{nT}$, the beam is spread over an area equivalent to a circle of about $40000 \mathrm{~km}$ in diametre, corresponding to a flux of $5 \times 10^{-6} \mathrm{~cm}^{-2} \mathrm{~s}^{-1}$ at $I_{e}=10 \mu \mathrm{A}$. Both beam spreading or focusing have been neglected for this estimation. Furthermore, the CIS instrument is insensitive in the mass range of indium.

The observed effects causing problems for the wire-boom electric-field experiment EFW remain to be analysed. One candidate hypothesis is based on the notion that the higherenergy photoelectrons that no longer return to the spacecraft where they had contaminated the particle measurements, now have to flow into the ambient plasma. This flow is associated with a reconfiguration (expansion) of the photo-sheath around the spacecraft, which is observed even at a $44 \mathrm{~m}$ distance. Whether or not the space charge carried by the ion beam itself contributes to changes in the sheath to any significant and measurable extent for probe and particle instruments remains to be analysed as well. From the initial analysis of the particle data, one could not detect any features that would point in this direction. 


\subsection{Operational profile}

During the first months of the mission, the apogee of the Cluster spacecraft was in the sunward sector, and major fractions of the time were spent in the magnetosheath and in the solar wind. Only during intervals of $<10$ hours between perigee and outbound or inbound magnetopause crossings, respectively, were more tenuous plasma regions crossed. In order to avoid a waste of indium resources in regions where the ion beam would only marginally further reduce the spacecraft potential, the instruments were arranged so that they were only active between the exit from the radiation belts, up until two hours after the nominal time of the outbound magnetopause crossing, and vice versa for the inbound sections of the orbits.

\section{Conclusions}

- The instrument ASPOC has demonstrated the capability of reducing the spacecraft potential to values which already significantly improve the conditions for plasma measurements, e.g. to $\approx 7 \mathrm{~V}$ (using $10 \mu \mathrm{A}$ ion current) or $\approx 5 \mathrm{~V}($ at $20 \mu \mathrm{A})$.

- ASPOC also reduces the natural fluctuations of the potential and thus provides a stable basis for the interpretation of plasma measurements.

- A reduction of the spacecraft potential to $\approx 7 \mathrm{~V}$ is considered to be a significant improvement for plasma measurements in comparison with free floating potentials of up to $+50 \mathrm{~V}$; therefore, the default ion current for nominal operations has been set to $10 \mu \mathrm{A}$.

- In order to maximise the scientific return from the indium resources available, operations concentrate on regions with low plasma density, where the uncontrolled potential would significantly exceed $+7 \mathrm{~V}$.

- Tests of the "feedback mode" using the inter-experiment data link from EFW to control the potential were successful.

- No side effects of ASPOC on wave instruments were reported.

- ASPOC affects the electric field measurements by EFW. While studies are ongoing, time-sharing of operations has been agreed.

- ASPOC operations do not completely cover the data acquisition intervals of Cluster, which leaves room for investigations based on measurements of the uncontrolled spacecraft potential.

Acknowledgements. We gratefully acknowledge the work of many people involved in hardware or software related to ASPOC: B. Butler, G. Fremuth, K. Fritzenwallner, F. Giner, H. Jeszenszky, B. Johlander, C. Kürbisch, K. Kvernsveen, B. Kyrkjedelen, G. Laky, S.
Neukirchner, U. Nischelwitzer, R. Wallner. We also deeply appreciate the work of the Cluster Project Team at ESTEC, and the teams of Astrium, the operations centre at ESOC and the Joint Science Operations Centre which made the mission a success.

Topical Editor G. Chanteur thanks K. Tswenda for his help in evaluating this paper.

\section{References}

Décréau, P. M. E., Fergeau, D., Krannosels'kikh, V., Lévêque, M., Martin, P., Randriamboarison, O., Sené, F. X., Trotignon, J. G., Canu, P., Mögensen, P. B., and WHISPER Investigators: WHISPER, A resonance sounder and wave analyser: performances and perspectives for the Cluster mission, Space Sci. Rev., 79, 157193, 1997.

Escoubet, C. P., Pedersen, A., Schmidt, R., and Lindqvist, P. A.: Density in the magnetosphere inferred from ISEE 1 spacecraft potential, J. Geophys. Res., 102, 17 595, 1997.

Fehringer, M., Rüdenauer, F., and Steiger, W.: Space-proven indium liquid metal ion emitters for ion microthruster applications, Proc. 33rd AIAA/ASME/SAE/ASEE Joint Propulsion Conference, AIAA-97-3057, 1-11, 1997.

Feuerbacher, B. and Fitton, B.: Experimental investigation of photo-emission from satellite surface material, J. Appl. Phys., 43 4, 1563-1572, 1972.

Grard, R. J. L.: Properties of the satellite photoelectron sheath derived from photoemission laboratory results, J. Geophys. Res., 78, 2885-2906, 1973.

Gustafsson, G., Boström, R., Holback, B., Holmgren, G., Lundgren, A., Stasiewicz, K., Ahlen, v, Mozer, F. S., Pankow, D., Harvey, P., Berg, P., Ulrich, R., Pedersen, A., Schmidt, R., Butler, A., Fransen, A. W. C., Klinge D., THomsen, M., Fälthammar, C.-G., Lindqvist, P.-A., Chrinstenson, S., Holtet, J., Lybekk, B., Sten, T. A., Tanskanen, P., Lappalainen, K., and Wygant, J.: The electric field and wave experiment for the Cluster mission, Space Sci. Rev., 79, 137-156, 1997.

Johnstone, A. D., Burge, S., Carter, P. J., Coates, A. J., Coker, A. J., Fazakerley, A. N., Grande, M., Gowan, R. A., Gurgiolo, C., Hancock, B. K., Narheim, B., Preece, A., Sheather, P. H., Winningham, J. D., and Woodliffe, R. D.: PEACE: A plasma electron and current experiment, Space Sci. Rev., 79, 351-398, 1997.

Kingham, D. R. and Swanson, L. W.: Mechanics of ion formation in Liquid Metal Ion Sources, Appl. Phys., A34, 123, 1984.

Mahoney, J. F., Yahiku, A. Y., Daley, H. L., Moore, R. D., and Perel, J.: Electrohydrodynamic ion source, J. Appl. Phys., 40, 5101-5106, 1969.

Moore, T. E., Chappell, C. R., Chandler, M. O., Fields, S. A., Pollock, C. J., Reasoner, D. L., Young, D. T., Burch, J. L., Eaker, N., Waite, Jr., J. H., McComas, D. J., Nordholdt, J. E., Thomsen, M. F., Berthelier, J. J., and Robson, R.: The Thermal Ion Dynamics Experiment and Plasma Source Instrument, Space Sci. Rev., 71, 409-458, 1995.

Mott-Smith, H. and Langmuir, I.: The theory of collectors in gaseous discharges, Phys. Rev., 28, 727, 1926.

Olsen, R. C.: The hidden ion population of the magnetosphere, J. Geophys. Res., 87, 3481-3488, 1982.

Pedersen, A., Chapell, C. R., Knott, K., and Olsen, R. C.: Methods for keeping a conductive spacecraft near the plasma potential, In: Spacecraft Plasma Interactions and Their Influence on Field and Particle Measurements, Proceedings of the 17th ESLAB Symposium, ESA SP-198, 185-190, 1983. 
Pedersen, A.: Solar wind and magnetosphere plasma diagnostics by spacecraft electrostatic potential measurements, Ann. Geophysicae, 13, 118-129, 1995.

Rème, H., et al.: The Cluster Ion Spectrometry (CIS) Experiment, Space Sci. Rev., 79, 303-350, 1997.

Riedler, W., Torkar, K., Rüdenauer, F., Fehringer, M., Pedersen, A., Schmidt, R., Grard, R. J. L., Arends, H., Narheim, B. T., Troim, J., Torbert, R., Olsen, R. C., Whipple, E., Goldstein, R., Valavanoglou, N., and Zhao, H.: Active spacecraft potential control, Space Sci. Rev., 79, 271-302, 1997.

Rüdenauer, F. G., Steiger, W., Studnicka, H., and Pollinger, P.: Int. J. Mass Spectrom. Ion Proc., 77, 63, 1987.

Schmidt, R., Schriver, D., and Ashour-Abdalla, M.: Plasma response to the emission of very weak ion beams for spacecraft potential control, J. Geophys. Res., 97, 14 959-14 965 ,1992.

Schmidt, R., Arends, H., Pedersen, A., Fehringer, M., Rüdenauer, F., Steiger, W., Narheim, B. T., Svenes, R., Kvernsveen, K., Tsuruda, K., Hayakawa, H., Nakamura, M., Riedler, W., and Torkar, K.: A novel medium-energy ion emitter for active spacecraft potential control, Rev. Sci. Inst., 64, 8, 2293-2297, 1993.

Schmidt, R., Arends, H., Pedersen, A., Rüdenauer, F., Fehringer, M., Narheim, B. T., Svenes, R., Kvernsveen, K., Tsuruda, K., Mukai, T., Hayakawa, H., and Nakamura, M.: Results from active spacecraft potential control on the Geotail spacecraft, J.
Geophys. Res., 100, A9, 17 253-17 259, 1995.

Szita, S., Fazakerley, A. N., Carter, P. J., James, A. M., Travnicek, P., Watson, G., André, M., Eriksson, A., and Torkar, K.: Cluster PEACE observations of electrons of spacecraft origin, Ann. Geophysicae, this issue, 2001.

Taylor, G. I.: Disintegration of water drops in an electric field, Proc. Royal Soc., (London), A280, 383, 1964.

Torkar, K., Veselov, M. V., Afonin, V. V., Arends, H., Fehringer, M., Fremuth, G., Fritzenwallner, K., Galperin, Yu. I., Kozlov, A. I., Pedersen, A., Perraut, S., Riedler, W., Rüdenauer, F., Schmidt, R., Smit, A., Valavanoglou, N., and Zinin, L. V.: An experiment to study and control the Langmuir sheath around INTERBALL, Ann. Geophysicae, 16, 1086-1096, 1998.

Torkar, K., Riedler, W., Fehringer, M., Rüdenauer, F., Escoubet, C. P., Arends, H., Narheim, B. T., Svenes, K., McCarthy, M. P., Parks, K., Lin, R. P., and Rème, H.: Spacecraft potential control aboard Equator-S as a test for Cluster-II, Ann. Geophysicae, 17, 1582-1591, 1999.

Whipple, E. C.: Potentials of surfaces in space, Rept. Prog. Phys., 44, 1197-1250, 1981.

Zhao, H., Schmidt, R., Escoubet, C. P., Torkar, K., and Riedler, W.: Self-consistent determination of the electrostatic potential barrier due to the photoelectron sheath near a spacecraft, J. Geophys. Res., 101, A7, 15 653-15 659, 1996. 